\title{
Small interfering RNAs suppress the expression of endogenous and GFP-fused epidermal growth factor receptor (erbB1) and induce apoptosis in erbB1-overexpressing cells
}

\author{
Peter Nagy, Donna J. Arndt-Jovin, and Thomas M. Jovin* \\ Department of Molecular Biology, Max Planck Institute for Biophysical Chemistry, Am Fassberg 11, D-37077 Göttingen, Germany
}

Received 6 August 2002, revised version received 28 October 2002

\begin{abstract}
Deregulated and excessive expression of epidermal growth factor receptor (EGFR or erbB1), a transmembrane receptor tyrosine kinase specific for the epidermal growth factor (EGF), is a feature and/or cause of a wide range of human cancers, and thus inhibition of its expression is potentially therapeutic. In RNA interference (RNAi), duplexes of 21-nucleotide RNAs (small interfering RNA, siRNA) corresponding to mRNA sequences of particular genes are used to efficiently inhibit the expression of the target proteins in mammalian cells. Here we show that by using RNAi the expression of endogenous erbB1 can be specifically and extensively (90\%) suppressed in A431 human epidermoid carcinoma cells. As a consequence, EGF-induced tyrosine phosphorylation was inhibited and cell proliferation was reduced due to induction of apoptosis. We established an inverse correlation between the level of expressed erbB1 and EGF sensitivity on a cell-by-cell basis using flow cytometry. A431 cells expressing endogenous erbB1 were transfected with erbB1 fused C-terminally to enhanced green fluorescent protein (EGFP). Selective inhibition of the expression of the fusion protein was achieved with an siRNA specific for the EGFP mRNA, whereas the erbB1-specific siRNAs inhibited the expression of both molecules. siRNA-mediated inhibition of erbB1 and other erbB tyrosine kinases may constitute a useful therapeutic approach in the treatment of human cancer.
\end{abstract}

(C) 2003 Elsevier Science (USA). All rights reserved.

Keywords: EGF receptor; erbB1; Inhibition of proliferation; RNA interference

\section{Introduction}

Cancer cells frequently overexpress growth factor receptors, resulting in both enhanced proliferation and dependence of tumor progression on the overexpression phenotype [1]. The erbB family of growth factor receptors are transmembrane receptor tyrosine kinases (RTKs) that are involved in the development and progression of a wide range of human cancers [2]. The four members of the family (erbB1-4) engage in a hierarchical network of interactions resulting in signal diversification [3]. Inhibition of the activity of one family member often induces profound effects by subverting the coordinated interactions within the network [4]. Thus, the erbB molecules constitute ideal targets

\footnotetext{
* Corresponding author. Fax: +49-552-201-1467.

E-mail address: tjovin@gwdg.de (T.M. Jovin).
}

in cancer therapy [5]. For example, a monoclonal antibody inhibits proliferation of erbB2-overexpressing cancer cells [6], and its humanized form (trastuzumab, Herceptin) is being employed in the successful immunotherapy of breast cancer $[7,8]$.

The epidermal growth factor receptor (EGFR or erbB1) is likewise overexpressed in a wide range of cancers [9] and thus constitutes another important therapeutic target $[2,10]$. A monoclonal anti-erbB1 antibody, cetuximab, is undergoing promising clinical trials in the treatment of lung and of head and neck cancers [11], as are a variety of small molecule ATP binding site inhibitors [5,12]. Although the detailed understanding of the biology and biochemistry of erbB proteins has led to the introduction of such receptortargeted drugs in the treatment of human cancers [5], new approaches and combined therapies are required due to therapeutic failure in individual cases and the evolution of drug resistance $[13,14]$. 
In addition to therapeutic approaches targeting the expressed proteins directly, their biosynthesis can also be inhibited, as exemplified by antisense oligonucleotides specific for erbB1 [15]. However, difficulties related to stability or specificity of the oligonucleotides or problems in target sequence selection hamper the widespread use of this approach [16]. More promising is the selective degradation of the corresponding mRNAs by RNA interference (RNAi), a process that avoids the global depression of protein synthesis induced by the double-stranded RNA-inducible interferon system present in mammalian cells [17]. In one implementation of RNAi, selective degradation of target mRNAs in mammalian cells is achieved by transfection with double-stranded, short interfering RNAs (siRNAs), leading to rapid and efficient degradation of the target [17]. Expression of siRNAs under the control of an RNA polymerase III promoter provides the means for achieving longterm suppression of protein synthesis $[18,19]$.

RNAi of transmembrane proteins, and of RTKs in particular, has not been reported to date. Consideration of the importance of the erbB family in human cancers and the efficiency of RNAi led us to design siRNAs against erbB1 and test their effects on the proliferation and EGF-induced responses of erbB1-(over)expressing cells. We show that siRNA-induced suppression of erbB1 expression results in significant inhibition of EGF-induced tyrosine phosphorylation and in induction of apoptosis in A431 human epidermoid carcinoma cells, a cell line widely used in the study of erbB1 because it expresses this RTK to a level of $\sim 2 \times 10^{6}$ [20]. The inhibitory effect of high concentrations of EGF on the proliferation of A431 was suppressed in siRNA-treated cells displaying a pronounced decrease in the expression level of erbB1. In A431 cells transfected to express an erbB1-EGFP (EGFP, enhanced green fluorescent protein) fusion protein in addition to the endogenous erbB1, inhibition of both molecules was achieved with an siRNA directed against the RTK moiety whereas selective suppression of the fusion protein ensued with an siRNA specific for the EGFP segment of the mRNA. The successful application of siRNA for inhibition of proliferation in erbB1overexpressing cells extends the list of available therapeutic modalities in the treatment of human cancer.

\section{Materials and methods}

\section{Cell culture and transfection}

Normal and stably transfected CHO, A431, and HeLa cells were cultured in Dulbecco's modified Eagle's medium supplemented with $10 \%$ FCS and penicillin/streptomycin (Invitrogen, Karlsruhe, Germany) in $5 \% \mathrm{CO}_{2}$. Cells were reseeded at a confluency of $30-60 \%$ in the absence of antibiotics 1 day before transfection. Transfection with plasmids and siRNAs were carried out with Lipofectamine2000 and Oligofectamine (Invitrogen), respectively, according to the manufacturer's specifications. Chemically synthesized siRNAs were kindly provided by Thomas Tuschl (Combinatorial Biochemistry Group, Max Planck Institute for Biophysical Chemistry, Göttingen, Germany) and were used at a concentration of $100 \mathrm{nM}$ in transfections.

Cells were kept in the absence of serum for 24-48 h before EGF stimulation. For flow cytometric evaluation cells were trypsinized, and trypsinization was stopped with $10 \%$ BSA to prevent possible activation of cells by serum.

\section{Western blotting}

Cells in a single well of a 24-well plate were lysed in SDS sample buffer, and proteins were separated on $7 \%$ polyacrylamide gels and transferred to nitrocellulose membranes. Anti-erbB1 monoclonal antibody F4 (E3138, Sigma, Schnelldorf, Germany) and anti-actin monoclonal antibody AC40 (A4700, Sigma) were used at 2000- and 500 -fold dilutions, respectively, followed by peroxidaseconjugated goat anti-mouse immunoglobulin for immunoblotting. Enhanced chemiluminescence (Amersham, Freiburg, Germany) was used for detection.

\section{Fluorescence microscopy}

Cells in 24-well plates were fixed in 3.7\% formaldehyde for $30 \mathrm{~min}$ on ice. Labeling with antibodies was carried out in the presence of $0.1 \%$ BSA and $0.1 \%$ Triton X-100. Anti-erbB1 mouse monoclonal antibody F4 (Sigma) antierbB1 rabbit polyclonal antibody sc-03 (Santa Cruz, Heidelberg, Germany), and anti-phosphotyrosine mouse monoclonal antibody sc-7020 (Santa Cruz) were used at 500-fold, 200-fold, and 1000-fold dilutions, respectively, followed by appropriate fluorescent secondary antibodies. Dual-labeling of erbB1 and phosphotyrosine was done with sc-03 and sc-7020, followed by labeling with Alexa488-goat antirabbit IgG and $\mathrm{Cy} 3$-goat anti-mouse IgG. No crossreaction of the antibodies was detected. Image processing was done with ImageJ (NIH, Bethesda, MD).

\section{Measurement of cell cycle distribution and apoptosis}

Cells were trypsinized and fixed in $70 \%$ ethanol at $4{ }^{\circ} \mathrm{C}$ overnight. After rehydration cells were labeled with an anti-erbB1 antibody as described above and stained with $100 \mu \mathrm{g} / \mathrm{ml}$ propidium iodide (Sigma) in the presence of 100 $\mu \mathrm{g} / \mathrm{ml}$ RNase for $60 \mathrm{~min}$ at $37^{\circ} \mathrm{C}$ followed by flow cytometric analysis. We confirmed the results obtained with this procedure with an alternative method based on staining cells in hypotonic fluorochrome solution [21]. Cell cycle analysis was carried out with the program Cylchred (Department of Hematology, College of Medicine, University of Wales, Cardiff, UK). 
Table 1

siRNAs against erbB1 and EGFP

\begin{tabular}{ccc}
\hline siRNA & Sense/antisense strands & $\begin{array}{l}\text { Starting position } \\
\text { of target } \\
\text { sequence }^{\mathrm{a}}\end{array}$ \\
\hline erbB1-1 & $\begin{array}{c}\text { 5'-CUCUGGAGGAAAAGAAAGUTT-3' } \\
\text { 3'-TTGAGACCUCCUUUUCUUUCA-5' }\end{array}$ & 316 \\
erbB1-2 & $\begin{array}{c}\text { 5'-CGUAAAGGAAAUCACAGGGTT-3' } \\
\text { 3'-TTGCAUUUCCUUUAGUGUCCC-5' }\end{array}$ & 1436 \\
erbB1-3 & 5'-CACAGUGGAGCGAAUUCCUTT-3' & 527 \\
& 3'-TTGUGUCACCUCGCUUAAGGA-5' $^{\prime}$ & \\
GFP-2 & 5'-GAACGGCAUCAAGGUGAACTT-3' & $1089(476)^{\mathrm{b}}$ \\
& 3'-TTCUUGCCGUAGUUCCACUUG-5' $^{\prime}$ &
\end{tabular}

a The starting positions of target sequences corresponding to the $5^{\prime}$ ends of the antisense strands of erbB1 and GFP siRNAs are given for the GI 12002211 and GI 1373318 sequences, respectively, relative to the first nucleotide of the published sequences.

${ }^{\mathrm{b}}$ The number in parentheses refers to the position of the target sequence in the GFP sequence in the GI 1373318 sequence.

\section{Flow cytometry}

Trypsinized cells were fixed in $3.7 \%$ formaldehyde (30 min on ice). Labeling of erbB2 was carried out with Mab OP15 (Calbiochem, Bad Soden, Germany) followed by staining with an appropriate secondary antibody. Labeling antibodies and conditions for erbB1 and phosphotyrosine staining were the same as those described above, except that secondary labeling of sc-7020 anti-phosphotyrosine antibody was performed with Cy5-tagged goat anti-mouse IgG. Flow cytometric analysis was with a Coulter Epics Elite flow cytometer equipped with a 488-nm argon ion laser and with a 633-nm HeNe laser. Receptor numbers were determined using Qifikit (DAKO, Hamburg, Germany). General flow cytometric data analysis was carried out using FCS Express (Denovo Software, Thornhill, Ontario, Canada). Two-parameter histograms are presented as contour plots [22].

Secondary staining of erbB1 on cells expressing erbB1EGFP was achieved using Mab F4 and Cy5-labeled antimouse IgG. Since the F4 antibody labeled both endogenous erbB1 and erbB1-EGFP, corrections were made to the amount of endogenous erbB1 according to the following equation: endogenous erbB $1=I_{\mathrm{Cy} 5}-C \cdot I_{\mathrm{EGFP}}$, where $I_{\mathrm{Cy} 5}$ and $I_{\mathrm{EGFP}}$ are the fluorescence intensities detected in the Cy5 and EGFP channels, respectively, $C$ is a constant describing the ratio of Cy5 to EGFP signals of erbB1-EGFP, as determined on CHO cells expressing erbB1-EGFP in the absence of endogenous erbB1. Parameter calculations were made in an Excel spreadsheet. In order to discriminate cells with normal and low erbB1 expression two Gaussian peaks were fitted to the histograms with Origin (Microcal, Northampton, MA), and the percentages of cells in the two subpopulations were calculated from the areas of the two peaks.

\section{Results}

\section{Inhibition of expression of transfected EGFP and erbBI in $\mathrm{CHO}$ cells}

We designed three double-stranded, 21-nucleotide-long siRNAs with TT dinucleotide $3^{\prime}$ overhangs against the coding sequence of erbB1 (GI 12002211) and one siRNA against EGFP (GI 1373318) (Table 1, Fig. 1). Chinese hamster ovary $(\mathrm{CHO})$ cells were transfected with an EGFP plasmid (pAD3) [23] or cotransfected with pAD3 and the GFP-2 siRNA. The ratio of positive cells was determined by fluorescence microscopy. The ratio of EGFP-positive cells decreased from $55 \%$ in cells transfected with plasmid alone to $6 \%$ in cells cotransfected with the GFP-2 siRNA (Figs. $2 \mathrm{~A}$ and $\mathrm{B})$. We also transfected $\mathrm{CHO}$ cells with an erbB1EGFP plasmid [24], in which the coding sequence of EGFP is fused to that of the C-terminus of erbB1 (Fig. 2C). Cotransfection of the erbB1-EGFP plasmid with the erbB1-1 siRNA resulted in a $90 \%$ reduction in the number of positive cells compared to transfection with the plasmid alone (Fig. 2D). We conclude that the GFP-2 and the erbB1-1 siRNAs can efficiently inhibit the expression of EGFP and erbB1-EGFP, respectively, in transfected CHO cells.

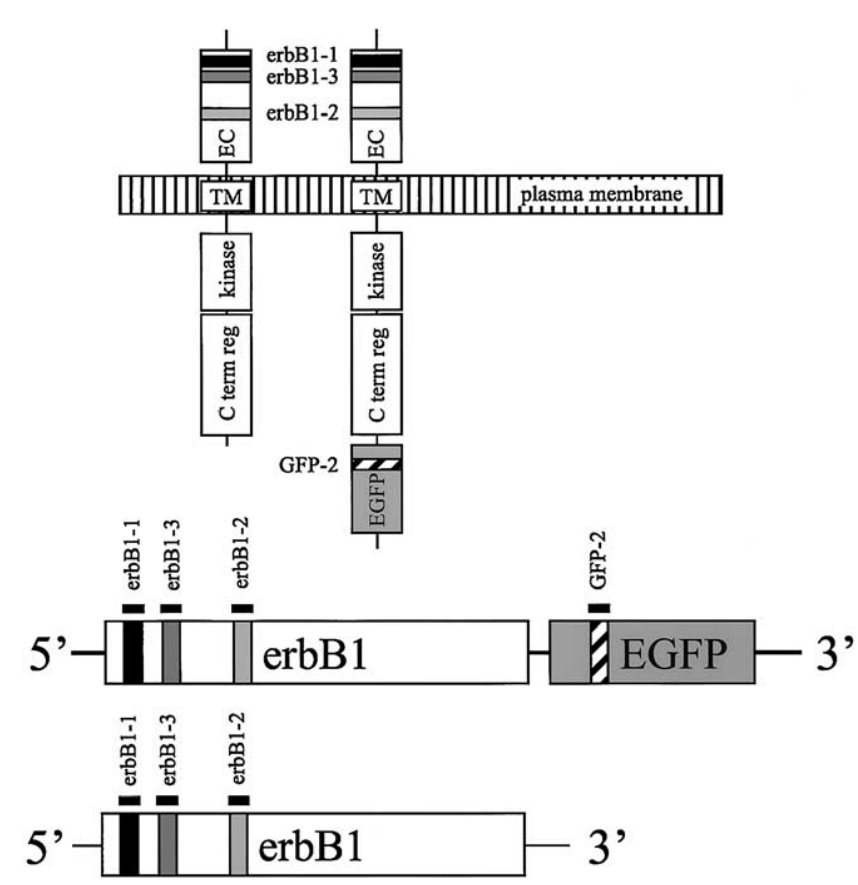

Fig. 1. Sequences and protein domains targeted by the erbB1 and GFP siRNAs. Simplified structures of the endogenous erbB1 and the erbB1EGFP protein (top) and mRNA (bottom) are shown (EC, extracellular domain; TM, transmembrane domain; $\mathrm{C}$ term reg, $\mathrm{C}$ terminal regulatory domain). The target sequences of the siRNAs and the corresponding segments in the proteins are indicated. 


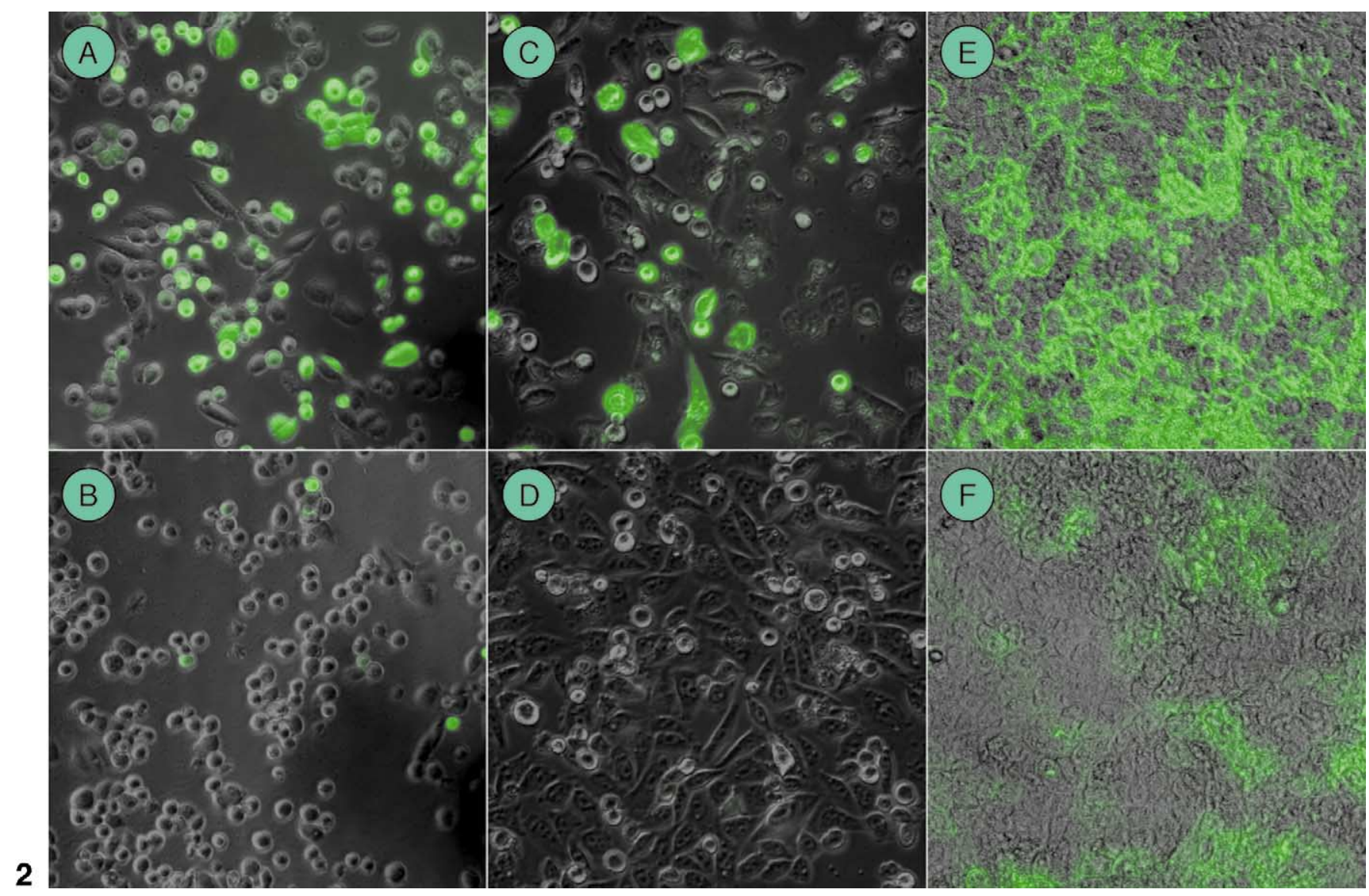

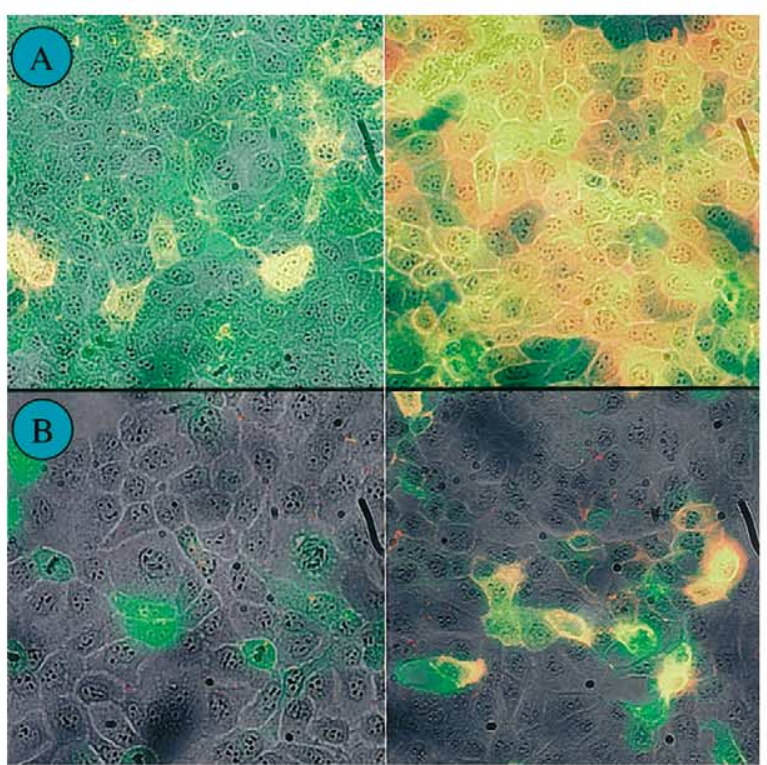

4

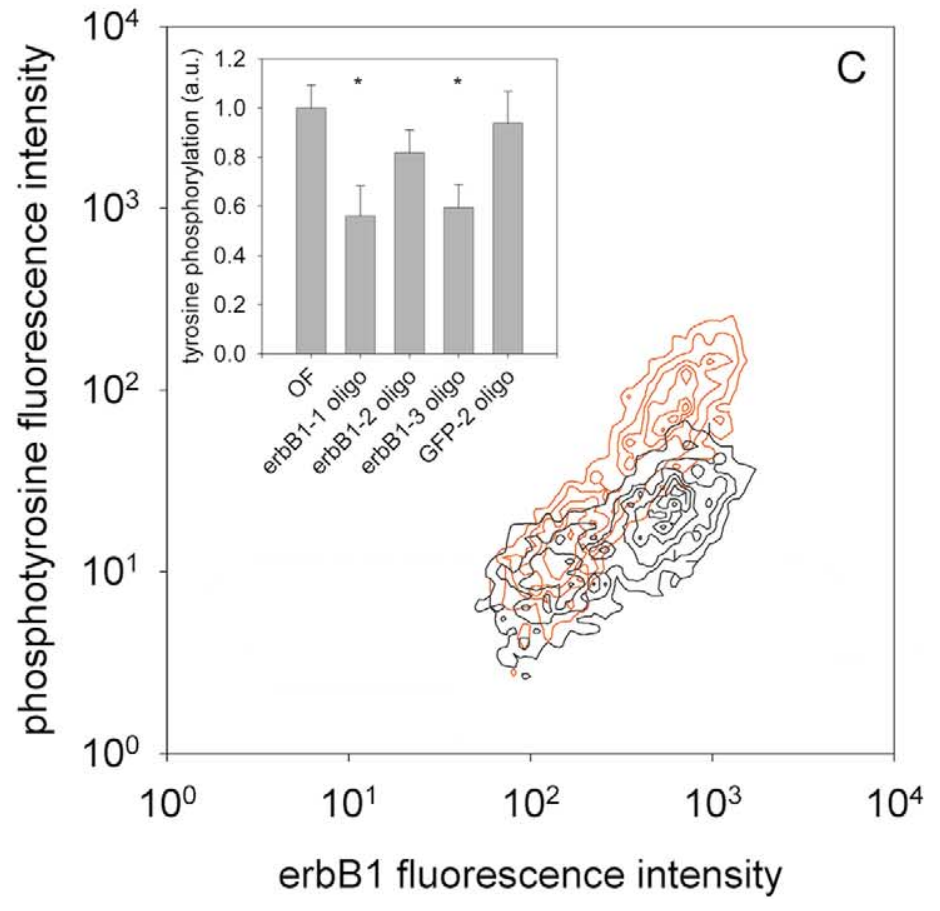

Fig. 2. siRNA-mediated inhibition of the expression of EGFP, erbB1, and erbB1-EGFP in CHO and A431 cells. Phase-contrast and overlaid fluorescence images taken $48 \mathrm{~h}$ after transfection are shown. CHO cells were transfected with the plasmid for EGFP (A) or erbB1-EGFP (C) or cotransfected with the EGFP plasmid and GFP-2 siRNA (B) or with erbB1-EGFP plasmid and erbB1-1 siRNA (D). A431 cells (E) and erbB1-1 siRNA-transfected A431 cells (F) were stained with an erbB1-specific antibody. 

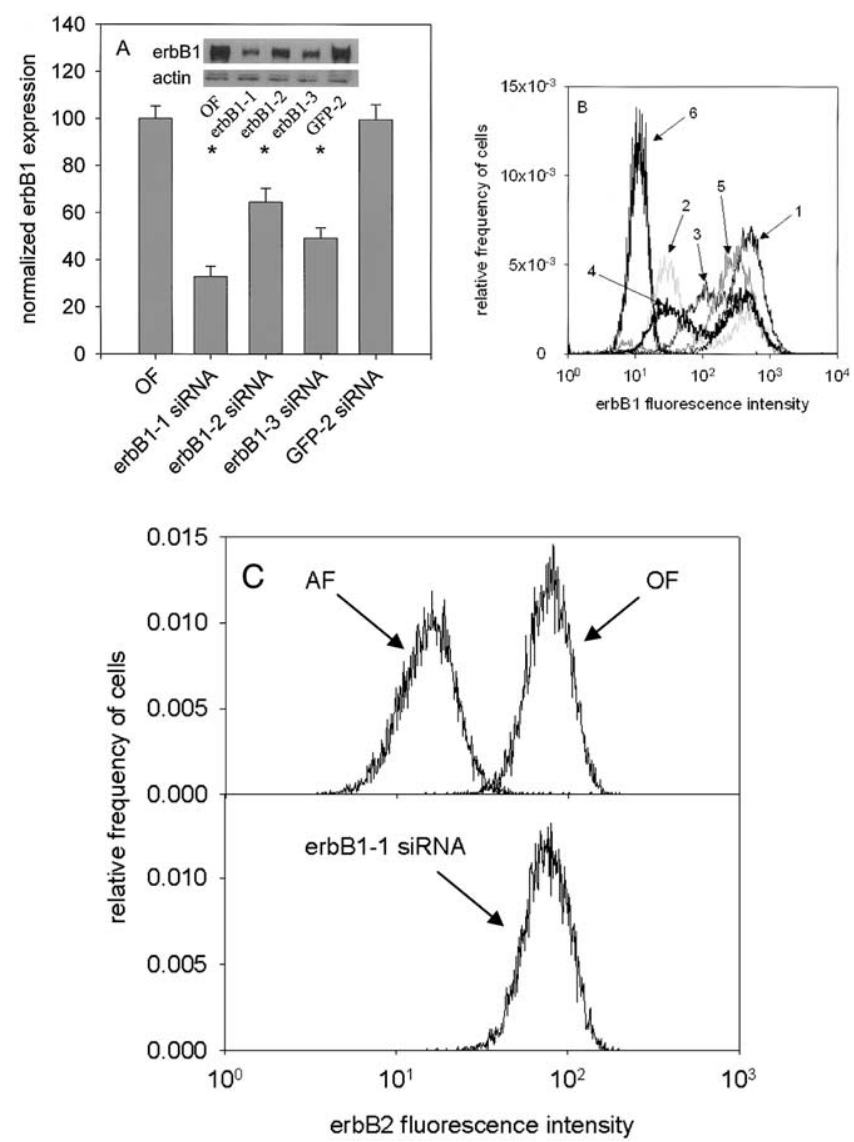

Fig. 3. Quantitative evaluation of inhibition of erbB protein expression in A431 cells evaluated by Western blotting and flow cytometry. (A, B) A431 cells were treated with oligofectamine (curve 1 in part $\mathrm{B}$ ) and transfected with erbB1-1 siRNA (curve 2), erbB1-2 siRNA (curve 3), erbB1-3 siRNA (curve 4), or an irrelevant siRNA (curve 5). ErbB1 expression was measured by Western blotting (A) and by flow cytometry (B) $48 \mathrm{~h}$ after transfection. Curve 6 in B displays cells stained with the secondary antibody alone. The Western blot was stained with an erbB1-specific antibody, then stripped, and reprobed with an antibody against actin. The expression of erbB1 was normalized by that of actin (A). Asterisks indicate significant difference from the oligofectamine-treated sample $(P<0.05)$. (C) A431 cells were transfected with the erbB1-1 siRNA or treated with oligofectamine only (OF) and stained with an anti-erbB2 antibody $48 \mathrm{~h}$ after transfection. The curve marked with AF displays oligofectamine-treated cells stained with secondary antibody only.

\section{Inhibition of the expression of endogenous erbB1 in A431 cells}

RNAi also served to suppress the expression of endogenous erbB1 in A431 epidermoid carcinoma cells. We trans- fected A431 cells with the three different erbB1 siRNAs, each of which was effective in reducing the expression of erbB1 according to fluorescence microscopy (Figs. 2E and F), Western blotting (Fig. 3A), and flow cytometric analysis (Fig. 3B). Western blotting applied to a heterogeneous cell population can be misleading in such a system due the residual fraction of untransfected cells. In contrast, flow cytometry has the virtue of yielding information about protein expression on a cell-by-cell basis with high statistical accuracy. Thus, it was possible to distinguish between untransfected and transfected (suppressed) cells and to accurately evaluate the specific RNAi effect on the latter (Fig. 3B). With both erbB1-1 and erbB1-3 siRNAs the histograms of cells with normal and inhibited erbB1 expression were well separated, permitting the determination of the fraction of suppressed cells and the expression levels of erbB1. The erbB1-1 and erbB1-3 siRNAs suppressed erbB1 expression in $69 \pm 5$ and $48 \pm 4 \%$ (mean \pm SD) of the cells, respectively. Compared to control A431 cells expressing $2 \times 10^{6} \pm 5 \times 10^{4}$ erbB1 molecules per cell, the erbB1-1 and erbB1-3 siRNA-suppressed populations displayed only $1.6 \times 10^{5} \pm 3 \times 10^{4}(8 \pm 2 \%$ of control A431 cells) and $1.8 \times 10^{5} \pm 4 \times 10^{4}(9 \pm 2 \%$ of control cells $)$ erbB1 receptors per cell, respectively. The number of receptors per cell was determined for the various cell populations by flow cytometric analysis based on calibrated microspheres (Qifikit, DAKO). Control experiments with the transfecting agent alone or a nonspecific siRNA demonstrated a negligible effect on erbB1 expression (Figs. 3A and B). Although the sequences of the erbB1 siRNAs were chosen so as to be specific for erbB1, we determined the effect of transfection with erbB1 siRNAs on the expression of a closely related protein, erbB2 (Fig. 3C), in A431 cells. None of the siRNAs had any significant influence on the expression of erbB2 (data shown for the erbB1-1 siRNA only). From the above control experiments we conclude that the RNAi effects were specific.

\section{EGF-induced tyrosine phosphorylation is inhibited in A431 cells transfected with the erbB1 siRNAs}

Tyrosine phosphorylation is pivotal in erbB1-mediated signal transduction [25] and inhibition of the kinase activity leads to reduced cell proliferation [26]. Therefore, we tested whether the RNAi-mediated suppression of erbB1 expression results in reduced tyrosine phosphorylation. A431 cells transfected with the erbB1 siRNAs, grown in the absence of

Fig. 4. Inhibition of EGF-induced tyrosine phosphorylation in erbB1 siRNA-transfected cells. Control (A) and erbB1-1 siRNA-transfected (B) A431 cells were stimulated with $1 \mathrm{ng} / \mathrm{ml} \mathrm{EGF}$ for $5 \mathrm{~min}$. The left and right panels show unstimulated and EGF-stimulated A431 cells, respectively. Cells were stained with an erbB1-specific antibody (green channel) and with a phosphotyrosine specific antibody (red channel), and overlaid fluorescence and phase-contrast images are shown. (C) Quiescent (black contours) and EGF-stimulated (red contours) erbB1-1 siRNA-transfected cells were stained with erbB1- and phosphotyrosine-specific antibodies and analyzed with flow cytometry. The insert in part $\mathrm{C}$ shows the quantitation of the flow cytometric results. Oligofectamine-treated and siRNA-transfected cells were stimulated with $1 \mathrm{ng} / \mathrm{ml} \mathrm{EGF}$ and the fluorescence intensity of phosphotyrosine-specific antibodies was measured. Asterisks indicate a significant difference from the oligofectamine-treated sample $(P<0.05)$. Cells were serum-starved for $48 \mathrm{~h}$ prior to EGF stimulation. 
serum for $48 \mathrm{~h}$, were stimulated with $1 \mathrm{ng} / \mathrm{ml}$ EGF for $5 \mathrm{~min}$ at $37^{\circ} \mathrm{C}$. Staining with erbB1- and phosphotyrosine-specific antibodies revealed that all erbB1 siRNAs inhibited EGFinduced tyrosine phosphorylation significantly (Figs. 4A and B; results for erbB1-1 siRNA). In the case of erbB1-2 siRNA, the lesser inhibition of erbB1 expression and the lower statistical reliability of fluorescence microscopy led us to perform parallel experiments using flow cytometry. Control and siRNA-transfected A431 cells were trypsinized and stimulated with $1 \mathrm{ng} / \mathrm{ml}$ EGF in suspension. Only the erbB1-1 and erbB1-3 siRNA inhibited EGF-induced tyrosine phosphorylation to a significant extent (Fig. 4C). The two methods of analysis are not entirely comparable in that the cells had to be removed from their growth substrate for flow cytometry, and perturbation of the cytoskeletal/extracellular matrix is known to activate protein kinases directly [27]. However, there was a clear correlation between the basal level of tyrosine phosphorylation and the expression of erbB1 in cells transfected with the erbB1-1 siRNA (Fig. 4). Cells transfected by siRNA exhibited a reduction in both erbB1 expression and tyrosine phosphorylation. Furthermore, cells with lower erbB1 expression did not respond to EGF stimulation at all, whereas untransfected cells with a high level of erbB1 expression in the transfected sample displayed a level of tyrosine phosphorylation similar to that of control cells (Fig. 4C).

\section{Proliferation and EGF-induced cell cycle responses are inhibited in erbB1 siRNA-transfected cells}

EGF exerts a concentration-dependent effect on A431 cells, at $0.1 \mathrm{ng} / \mathrm{ml}$ promoting cell proliferation, but at 1 $\mathrm{ng} / \mathrm{ml}$ inducing cell cycle arrest [28]. We determined whether siRNA-mediated inhibition of erbB1 expression interferes with the cell cycle arrest and proliferation-inducing effects of EGF and/or with cell proliferation in the presence of serum. All erbB1 siRNAs blocked the proliferation of A431 cells in $10 \%$ serum and in $0.1 \mathrm{ng} / \mathrm{ml}$ EGF equally well (by $\sim 80 \%$, Fig. $5 \mathrm{~A}$ ), i.e., regardless of the quantitative differences in erbB1 expression. An irrelevant siRNA did not significantly affect erbB1 expression (Fig. 3 ), but reduced cell proliferation to some extent (by $\sim 30 \%$ ), indicating that the transfection with siRNAs may partially and nonspecifically inhibit cell proliferation. To further investigate the specificity of the siRNA effects, we transfected HeLa cells, expressing $\sim 70000$ erbB1 molecules [29], with the siRNAs. The transfection efficiency with the erbB1 siRNAs determined by flow cytometry was very high $(\sim 100 \%)$ and resulted in a $\sim 75 \%$ decrease in the expression of erbB1 (not shown). Each erbB1 siRNA also reduced cell proliferation by $\sim 20-25 \%$ (not shown). Transfection of HeLa cells with the GFP-2 siRNA reduced cell proliferation by $\sim 20 \%$, an extent similar to that observed with A431 cells. We conclude that although the erbB1 siRNAs knock down protein expression, none exerted a specific effect on the proliferation of HeLa cells. We also tested the influence of the erbB1 siRNAs on the proliferation of a cell line (CHO) lacking erbB protein expression. The various siRNAs had only a negligible effect on the proliferation of CHO cells (data not shown).

We next investigated the cell cycle changes induced by the siRNAs in order to elucidate the mechanism of the erbB1 siRNA-induced decrease in cell proliferation. We observed a significant increase in the apoptotic fraction in cells transfected with the erbB1-1 siRNA compared to untransfected cells (Fig. 5B), whereas the cell cycle distribution of the nonapoptotic fraction was unaffected. Similar changes were observed with the other erbB1 siRNAs (not shown).

In contrast to the effect of all erbB1 siRNAs on cell proliferation, only the erbB1-1 and erbB1-3 siRNAs prevented the cell cycle arrest induced by $1 \mathrm{ng} / \mathrm{ml}$ EGF (Fig. $5 \mathrm{~A})$. These data correlated well with the efficiencies with which the siRNAs inhibit tyrosine phosphorylation induced by the same concentration of EGF (Fig. 4C). EGF at $1 \mathrm{ng} / \mathrm{ml}$ preferentially arrested the cells that were not transfected in the sample exposed to the erbB1 siRNA, as shown in the flow cytometric analysis of the populations (Fig. 5C). Thus, the fraction of the population exhibiting suppression by the erbB1-1 siRNA in the EGF-treated sample was $\sim 30 \%$ larger than that in the untreated one (Fig. 5C).

\section{The expression of erbB1-EGFP is selectively suppressed in an endogenous erbB1-expressing background by EGFP-targeted siRNAs}

Transfection of cells with GFP constructs is an established technique in cell biology. Selective manipulation of the expression of the transfected GFP constructs and of endogenous genes would be invaluable, but is difficult to achieve. We generated a clone of A431 cells (A4-erbB1), which expresses $1.3 \times 10^{6}$ erbB1-EGFP molecules/cell in addition to endogenous erbB1 $\left(1.8 \times 10^{6}\right.$ receptors/cell $)$ [24]. Transfection of A4-erbB1 cells with the erbB1 siRNAs decreased the expression of both the endogenous erbB1 and the erbB1-EGFP proteins (Fig. 6B). In contrast, the GFP-2 siRNA only inhibited the expression of the erbB1-EGFP construct (Fig. 6C).

\section{Discussion}

ErbB1 has long been considered an important oncoprotein in the development of human malignancies and is one of the emerging targets in tumor therapy [2]. Although considerable progress has been made in the application of oncoprotein-targeted antibodies and small molecule tyrosine kinase inhibitors, none of these agents is curative [5]. In an effort to find new approaches to target erbB1-overexpressing cancer cells, we set out to characterize the RNAiinduced knock-down of endogenous and transfected erbB1.

We achieved a significant inhibition of erbB1 expression 

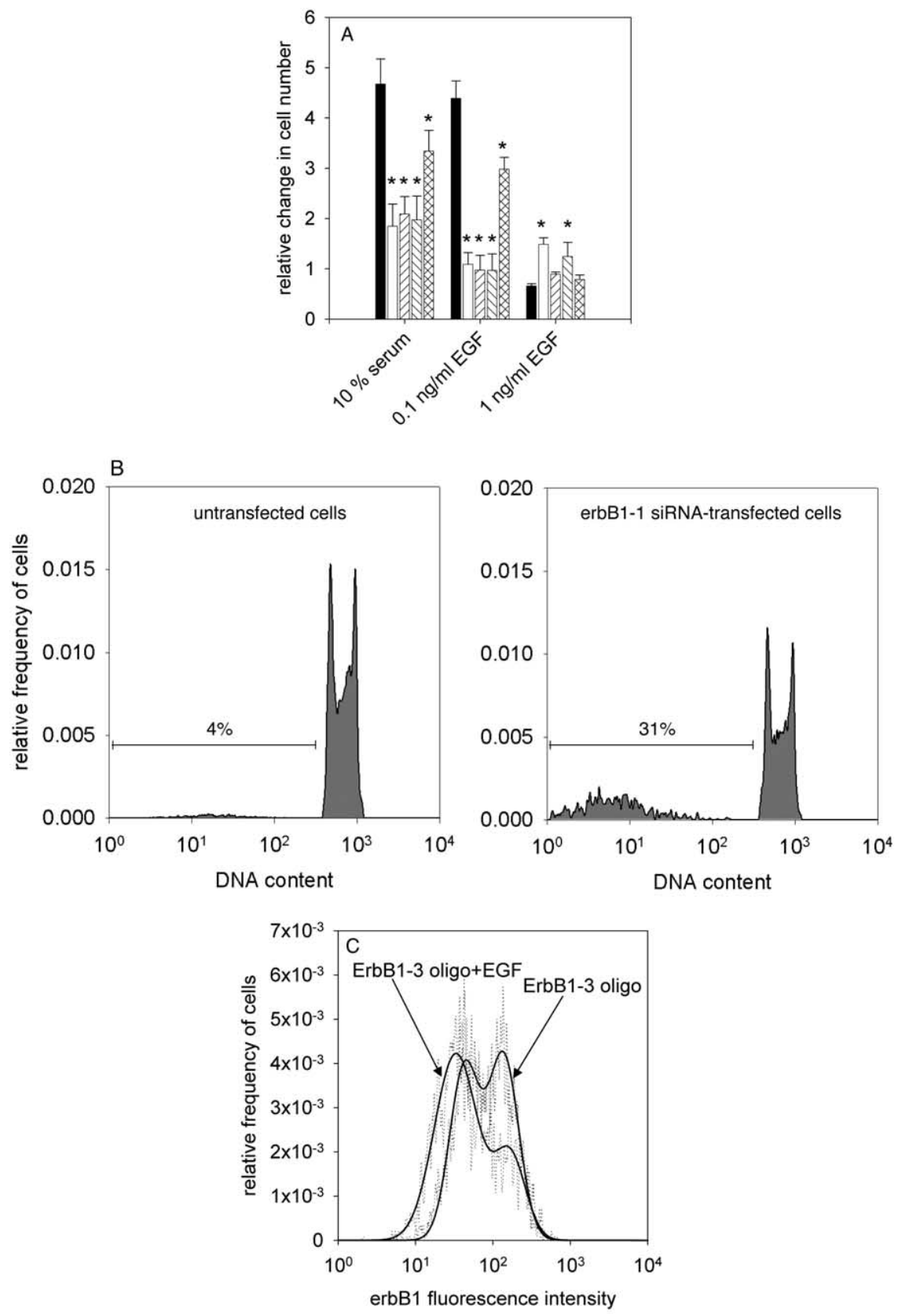

Fig. 5. ErbB1-specific siRNAs interfere with EGF-induced cell cycle changes. (A) A431 cells were treated with oligofectamine only (black) or transfected with erbB1-1 siRNA (white), erbB1-2 siRNA (left-hatched), erbB1-3 siRNA (right-hatched), or an irrelevant siRNA (GFP-2 siRNA, cross-hatched). At 12-h posttransfection cells were serum starved for an additional $24 \mathrm{~h}$ and then treated for $48 \mathrm{~h}$ as indicated on the horizontal axis before counting total cell number with a Coulter counter. The relative change in cell number $( \pm \mathrm{SD})$ over the 48 -h period after serum starvation is plotted. Asterisks indicate a significant difference from the oligofectamine-treated sample $(P<0.05)$. (B) A431 cells were transfected with the erbB1-1 siRNA. Eight hours after transfection they were serum-starved for $24 \mathrm{~h}$ and then cultured in the presence of $10 \%$ FCS for another $24 \mathrm{~h}$. Afterward they were stained with an anti-erbB1 antibody and propidium iodide. The graphs display the DNA content of the nontransfected (left) and knocked down (right) subpopulation, respectively. (C) Flow cytometric analysis of A431 cells transfected with erbB1-3 siRNA. At 12-h posttransfection cells were serum-starved for $24 \mathrm{~h}$, and then half of the population was stimulated with $1 \mathrm{ng} / \mathrm{ml}$ EGF for $24 \mathrm{~h}$. Flow cytometric histograms (dotted curves) and Gaussian fits thereof are shown for both EGF-treated and nontreated cells.

in A431 epidermoid carcinoma cells using three different siRNAs targeted to the coding region of the erbB1 mRNA (Figs. 2 and 3). Suppression of the expression of erbB1EGFP with siRNAs against the erbB1 or EGFP part of the
mRNA was dramatic in both transiently and stably transfected cells. The degree to which the expression of a given protein lends itself to inhibition by RNA interference depends on the half-life and synthesis rate of the protein. The 


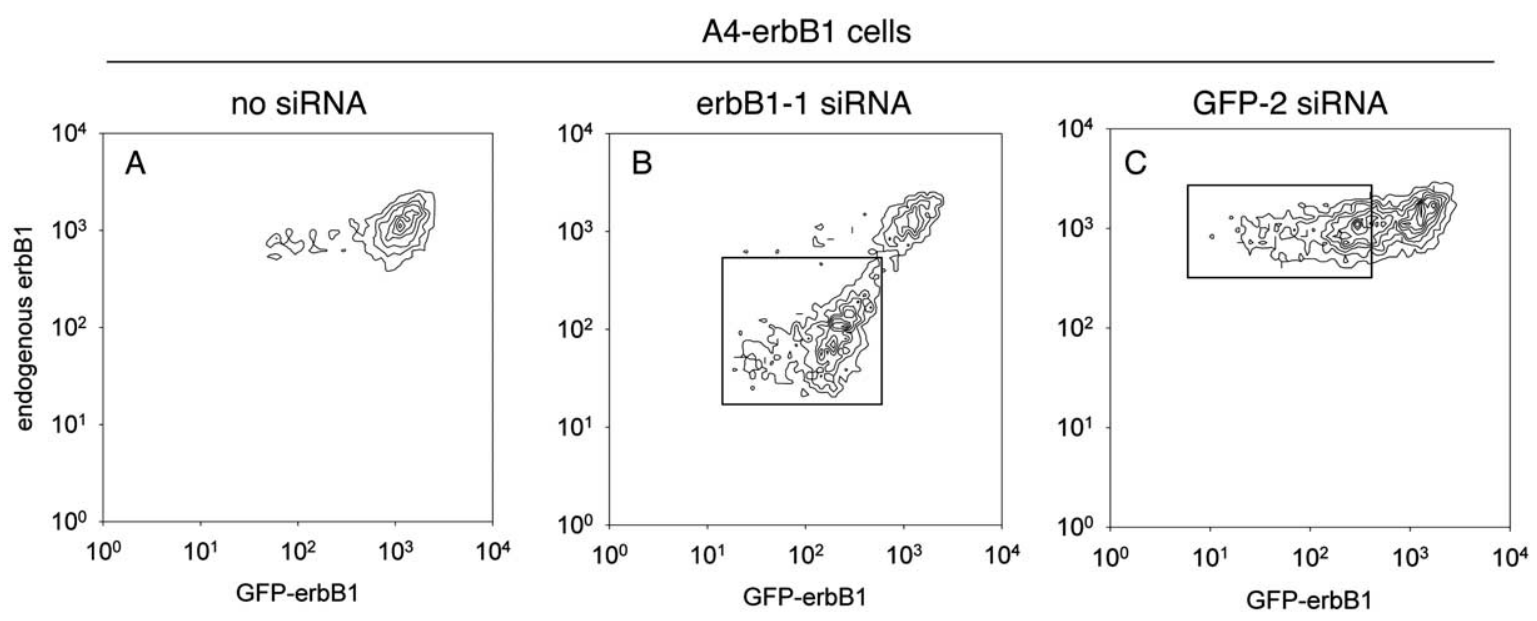

Fig. 6. Suppression of endogenous and erbB1-EGFP expression in A4-erbB1 cells. A4-erbB1 cells were treated with oligofectamine (A) or transfected with erbB1-1 siRNA (B) or GFP-2 siRNA (C). Flow cytometric contour plots were recorded $48 \mathrm{~h}$ after transfection. The rectangles indicate the position of the suppressed populations. In B, both endogenous erbB1 expression and EGFP-erbB1 expression were inhibited, whereas in C only the expression of erbB1-EGFP was inhibited.

turnover of erbB1 is considered to be much faster than that of other erbB proteins [30], implying that the latter may be more difficult to suppress using RNAi, because even if the biosynthesis of the protein is blocked, previously synthesized molecules persist in the plasma membrane for a relatively long time. Therefore, combination of RNAi with other approaches for downregulating erbB proteins, e.g., antibody [31] or tyrosine kinase inhibitors [32], may have additive or synergistic effects. The abundance of a target mRNA is also expected to influence the efficiency of RNAiinduced suppression of protein production. The fact that we successfully inhibited the expression of erbB1 in A431 cells in which the erbB1 gene is amplified 30-fold [33] provides evidence for the high potency of the RNA interference phenomenon [34].

We used both Western blotting and flow cytometry to measure the expression level of erbB1. The results from these two approaches were in quantitative agreement, but the heterogeneous expression of erbB1 after transfection of cells with siRNA rendered the Western blotting results misleading. Although the erbB1-1 siRNA induces a 90\% reduction in erbB1 expression in cells actually transfected by the siRNA, the overall reduction of erbB1 production, detected by Western blotting, was only $\sim 70 \%$, reflecting the weighted average of the protein production of siRNAtransfected and nontransfected cells. Therefore, the use of single-cell measurement techniques is to be encouraged, especially in the case of cell populations in which the fraction of transfected cells is low.

Although the expression of erbB1 in A431 cells was significantly reduced by RNAi, the suppressed cells still expressed 1.5-2 $2 \times 10^{5}$ erbB1 receptors per cell even in the case of the most effective siRNAs. The fact that these cells showed no increase in generalized tyrosine phosphorylation detectable with flow cytometry (Fig. 4C) suggests that an incomplete inhibition of erbB1 expression is sufficient to abolish growth factor-mediated signaling. Growth factor receptors appear to be clustered in submicrometer membrane microdomains [35], and receptor activation is believed to be largely [36], but not exclusively [37], confined to sites where receptors encounter their respective ligands. The activities of protein tyrosine kinases are counterbalanced by protein tyrosine phosphatases [38]. Therefore, activation of the tyrosine phosphorylation response may be completely switched off if the number of erbB1 molecules drops below a given threshold, since the balance of tyrosine phosphorylation and dephosphorylation may be shifted toward the latter process to a degree that switches off downstream signaling, i.e., via the MAPK cascade [39].

Only the two most efficient siRNAs (erbB1-1 and erbB1-3) suppressed both tyrosine phosphorylation (detected by flow cytometry) and the apoptosis/cell cycle arrest induced by a high concentration of EGF $(1 \mathrm{ng} / \mathrm{ml}$; Figs. 4C and 5A). On the other hand, all erbB1 siRNAs were equally effective in blocking cell proliferation in the presence of serum or at a low concentration $(0.1 \mathrm{ng} / \mathrm{ml})$ of EGF (Fig. $5 \mathrm{~A})$. The induction of proliferation and apoptosis/cell cycle arrest may be differentially sensitive to the amount of residual erbB1 expression. That is, the least efficient erbB1 siRNA (erbB1-2) may block the low-dose, but not the highdose, effects of EGF.

At first sight it may seem that the inhibitory effect of the erbB1 siRNAs on the EGF-induced proliferation inhibiting response is weak. However, the number of cells increased 1.5-fold in the erbB1-1 siRNA-transfected sample treated with $1 \mathrm{ng} / \mathrm{ml} \mathrm{EGF}$, which is close to the 1.8 -fold increase observed in the erbB1-1 siRNA-transfected sample in the presence of $10 \%$ FCS. That is, the growth inhibitory effect of $1 \mathrm{ng} / \mathrm{ml}$ EGF was virtually completely inhibited. The protective effect of erbB1 siRNA transfection against the proliferation inhibiting effect of a high concentration of EGF is also supported by the flow cytometric measurement 
of the relative ratios of the subpopulations with normal and inhibited erbB1 expressions. Cells in which erbB1 expression was low due to transfection with the erbB1 siRNA were protected from the apoptosis/cell cycle arrest-inducing effect of $1 \mathrm{ng} / \mathrm{ml}$ EGF. Therefore, the fraction of this subpopulation in the EGF-treated sample was larger than in the control (Fig. 5C).

Inhibition of the activity of erbB 1 by small molecule tyrosine kinase inhibitors or antibodies reduces cell proliferation either by blocking cell cycle progression from the G1 phase [12,40] or by inducing apoptosis [41,42]. A431 cells transfected with the erbB1 siRNAs showed a rate of apoptosis significantly higher than that of control cells, implying a primarily cytotoxic rather than a cytostatic effect of these agent.

The antiproliferative effect of erbB1 siRNAs has obvious implications for cancer therapy. It is known that overexpression of erbB1 is associated with poor prognosis in many epithelial cancers including head and neck, breast, colon, and lung tumors [43]. Overexpression of erbB1 leads to activation of the MAPK pathway and a high proliferation index [44]. Although erbB1 is expressed in adult tissues and participates in physiological processes such as wound healing [45], it is expected that cells with a very high expression of the receptor show enhanced sensitivity to inhibition of erbB1 expression or function. Anti-erbB1 antibody treatment is well tolerated in patients [46], but treatment with erbB1-specific tyrosine kinase inhibitors does have side effects [47] probably related to the inhibition of erbB1 activity in normal tissues [44]. Therefore, it is important to determine how cells with different levels erbB1 expression react to siRNA-mediated inhibition of erbB1 synthesis. We found that the proliferation of siRNA-treated A431 cells with a residual expression of $\sim 2 \times 10^{5}$ erbB1 proteins was inhibited, whereas that of HeLa cells expressing $\sim 12 \times 10^{4}$ copies of the protein was not. Our results suggest that cells with high erbB1 expression show enhanced sensitivity to the knock-down of erbB1 expression compared to cells with a lower expression level. This finding is in agreement with that of Sirotnak el al. [48], who reported a correlation between erbB1 expression and the sensitivity of cell proliferation to an erbB1-specific tyrosine kinase inhibitor. However, contradictory results have also been published [12]. We did not find evidence for a significant effect of erbB1 siRNAs on the proliferation of CHO cells that do not express erbB1. This finding suggests that the erbB1 siRNAs do not inhibit cell proliferation nonspecifically. Taken together, these results imply that although erbB 1 is essential for physiological processes in adults, cancer cells with deregulated erbB1 expression exhibit an increased sensitivity to erbB1-targeted drugs, thereby increasing the therapeutic index of such treatments. This circumstance may render erbB1 siRNAs effective agents in the treatment of erbB1overexpressing cancers.

Selective suppression of the expression of a GFP-tagged transfected protein is a desirable experimental goal in cases where modulation of the expression level of the GFP construct is required. In this study, we were able to selectively inhibit erbB1-EGFP expression in A4-erbB1 cells expressing endogenous erbB1 (Fig. 6). This result would seem to argue against the generation of secondary siRNAs specific for regions $5^{\prime}$ from the target sequence of the original siRNA [49]. However, even if secondary siRNAs were to be generated, selective suppression of certain GFP constructs should still be feasible, given the pronounced directionality and distance dependence of the process [50].

In summary, we have shown that erbB1-specific siRNAs mediate efficient and selective inhibition of erbB1 expression in cells expressing erbB1 as an endogenous or ectopic protein. The degree of suppression was sufficient to inhibit cell proliferation and cell cycle arrest of A431 epidermoid carcinoma cells induced by low and high levels of EGF, respectively, mirroring the lack of EGF-induced tyrosine phosphorylation. RNAi-mediated inhibition of erbB1 function holds great promise for the treatment of human cancer in conjunction with tyrosine kinase inhibitors and monoclonal antibodies [5]. We are presently extending the approach to other members of the erbB family.

\section{Acknowledgments}

We are greatly indebted to Thomas Tuschl and Sayda Elbashir for advice and discussions about the RNAi experiments and provision of facilities for synthesizing the siRNAs. This work was supported by EU Grant FP5 QLRT1999-3126 ("ErbB in Breast Tumor") and the Max Planck Society. P.N. was the recipient of a fellowship from the EU Grant.

\section{References}

[1] Y. Yarden, M.X. Sliwkowski, Untangling the ErbB signalling network, Nat. Rev. Mol. Cell. Biol. 2 (2001) 127-137.

[2] Y. Yarden, The EGFR family and its ligands in human cancer: signalling mechanisms and therapeutic opportunities, Eur. J. Cancer 37 (Suppl. 4) (2001) S3-S8.

[3] E. Tzahar, H. Waterman, X. Chen, G. Levkowitz, D. Karunagaran, S. Lavi, B.J. Ratzkin, Y. Yarden, A hierarchical network of interreceptor interactions determines signal transduction by Neu differentiation factor/neuregulin and epidermal growth factor, Mol. Cell Biol. 16 (1996) 5276-5287.

[4] M.M. Moasser, A. Basso, S.D. Averbuch, N. Rosen, The tyrosine kinase inhibitor ZD1839 ("Iressa") inhibits HER2-driven signaling and suppresses the growth of HER2-overexpressing tumor cells, Cancer Res. 61 (2001) 7184-7188.

[5] L.K. Shawver, D. Slamon, A. Ullrich, Tyrosine kinase inhibitors in cancer therapy, Cancer Cell 1 (2002) 117-123.

[6] J. Baselga, L. Norton, J. Albanell, Y.M. Kim, J. Mendelsohn, Recombinant humanized anti-HER2 antibody (Herceptin) enhances the antitumor activity of paclitaxel and doxorubicin against HER2/neu overexpressing human breast cancer xenografts, Cancer Res. 58 (1998) 2825-2831.

[7] J. Baselga, Phase I and II clinical trials of trastuzumab, Ann. Oncol. 12 (Suppl. 1) (2001) S49-S55. 
[8] M.D. Pegram, A. Lipton, D.F. Hayes, B.L. Weber, J.M. Baselga, D. Tripathy, D. Baly, S.A. Baughman, T. Twaddell, J.A. Glaspy, D.J. Slamon, Phase II study of receptor-enhanced chemosensitivity using recombinant humanized anti-p185HER2/neu monoclonal antibody plus cisplatin in patients with HER2/neu-overexpressing metastatic breast cancer refractory to chemotherapy treatment, J. Clin. Oncol. 16 (1998) 2659-2671.

[9] D.S. Salomon, R. Brandt, F. Ciardiello, N. Normanno, Epidermal growth factor-related peptides and their receptors in human malignancies, Crit. Rev. Oncol. Hematol. 19 (1995) 183-232.

[10] J. Mendelsohn, J. Baselga, The EGF receptor family as targets for cancer therapy, Oncogene 19 (2000) 6550-6565.

[11] D.M. Shin, N.J. Donato, R. Perez-Soler, H.J. Shin, J.Y. Wu, P. Zhang, K. Lawhorn, F.R. Khuri, B.S. Glisson, J. Myers, G. Clayman, D. Pfister, J. Falcey, H. Waksal, J. Mendelsohn, W.K. Hong, Epidermal growth factor receptor-targeted therapy with $\mathrm{C} 225$ and cisplatin in patients with head and neck cancer, Clin. Cancer Res. 7 (2001) 1204-1213.

[12] F. Ciardiello, R. Caputo, R. Bianco, V. Damiano, G. Pomatico, S. De Placido, A.R. Bianco, G. Tortora, Antitumor effect and potentiation of cytotoxic drugs activity in human cancer cells by ZD-1839 (Iressa), an epidermal growth factor receptor-selective tyrosine kinase inhibitor, Clin. Cancer Res. 6 (2000) 2053-2063.

[13] J. Baselga, The EGFR as a target for anticancer therapy-focus on cetuximab, Eur. J. Cancer 37 (Suppl. 4) (2001) S16-S22.

[14] P.C. Bishop, T. Myers, R. Robey, D.W. Fry, E.T. Liu, M.V. Blagosklonny, S.E. Bates, Differential sensitivity of cancer cells to inhibitors of the epidermal growth factor receptor family, Oncogene 21 (2002) 119-127.

[15] K. Fang, M.H. Chen, Transfection of anti-sense complementary DNA of human epidermal-growth-factor receptor attenuates the proliferation of human non-small-cell-lung-cancer cells, Int. J. Cancer 81 (1999) 471-478.

[16] K.Y. Jen, A.M. Gewirtz, Suppression of gene expression by targeted disruption of messenger RNA: available options and current strategies, Stem Cells 18 (2000) 307-319.

[17] S.M. Elbashir, J. Harborth, W. Lendeckel, A. Yalcin, K. Weber, T. Tuschl, Duplexes of 21-nucleotide RNAs mediate RNA interference in cultured mammalian cells, Nature 411 (2001) 494-498.

[18] T.R. Brummelkamp, R. Bernards, R. Agami, A system for stable expression of short interfering RNAs in mammalian cells, Science 296 (2002) 550-553.

[19] M. Miyagishi, K. Taira, U6 promoter driven siRNAs with four uridine $3^{\prime}$ overhangs efficiently suppress targeted gene expression in mammalian cells, Nat. Biotechnol. 20 (2002) 497-500.

[20] J. Filmus, M.N. Pollak, R. Cailleau, R.N. Buick, MDA-468, a human breast cancer cell line with a high number of epidermal growth factor (EGF) receptors, has an amplified EGF receptor gene and is growth inhibited by EGF, Biochem. Biophys. Res. Commun. 128 (1985) 898-905.

[21] I. Nicoletti, G. Migliorati, M.C. Pagliacci, F. Grignani, C. Riccardi, A rapid and simple method for measuring thymocyte apoptosis by propidium iodide staining and flow cytometry, J. Immunol. Methods 139 (1991) 271-279.

[22] H.M. Shapiro, Overture, in: Practical Flow Cytometry, Wiley-Liss, New York, 1995.

[23] R.H. Kehlenbach, A. Dickmanns, L. Gerace, Nucleocytoplasmic shuttling factors including Ran and CRM1 mediate nuclear export of NFAT in vitro, J. Cell Biol. 141 (1998) 863-874.

[24] R. Brock, I.H. Hamelers, T.M. Jovin, Comparison of fixation protocols for adherent cultured cells applied to a GFP fusion protein of the epidermal growth factor receptor, Cytometry 35 (1999) 353-362.

[25] J. Schlessinger, Cell signaling by receptor tyrosine kinases, Cell 103 (2000) 211-225.

[26] C.L. Arteaga, D.H. Johnson, Tyrosine kinase inhibitors-ZD1839 (Iressa), Curr. Opin. Oncol. 13 (2001) 491-498.
[27] D.H. Campbell, R.L. Sutherland, R.J. Daly, Signaling pathways and structural domains required for phosphorylation of EMSI/cortactin, Cancer Res. 59 (1999) 5376-5385.

[28] L. Cao, Y. Yao, V. Lee, C. Kiani, D. Spaner, Z. Lin, Y. Zhang, M.E. Adams, B.B. Yang, Epidermal growth factor induces cell cycle arrest and apoptosis of squamous carcinoma cells through reduction of cell adhesion, J. Cell Biochem. 77 (2000) 569-583.

[29] T. Ringerike, E. Stang, L.E. Johannessen, D. Sandnes, F.O. Levy, I.H. Madshus, High-affinity binding of epidermal growth factor (EGF) to EGF receptor is disrupted by overexpression of mutant dynamin (K44A), J. Biol. Chem. 273 (1998) 16639-16642.

[30] J. Baulida, M.H. Kraus, M. Alimandi, P.P. Di Fiore, G. Carpenter, All ErbB receptors other than the epidermal growth factor receptor are endocytosis impaired, J. Biol. Chem. 271 (1996) 5251-5257.

[31] M.X. Sliwkowski, J.A. Lofgren, G.D. Lewis, T.E. Hotaling, B.M. Fendly, J.A. Fox, Nonclinical studies addressing the mechanism of action of trastuzumab (Herceptin), Semin. Oncol. 26 (1999) 60-70.

[32] A. Citri, I. Alroy, S. Lavi, C. Rubin, W. Xu, N. Grammatikakis, C. Patterson, L. Neckers, D.W. Fry, Y. Yarden, Drug-induced ubiquitylation and degradation of ErbB receptor tyrosine kinases: implications for cancer therapy, EMBO J. 21 (2002) 2407-2417.

[33] G.T. Merlino, Y.H. Xu, S. Ishii, A.J. Clark, K. Semba, K. Toyoshima, T. Yamamoto, I. Pastan, Amplification and enhanced expression of the epidermal growth factor receptor gene in A431 human carcinoma cells, Science 224 (1984) 417-419.

[34] A. Fire, S. Xu, M.K. Montgomery, S.A. Kostas, S.E. Driver, C.C. Mello, Potent and specific genetic interference by doublestranded RNA in Caenorhabditis elegans, Nature 391 (1998) 806811.

[35] P. Nagy, A. Jenei, A.K. Kirsch, J. Szöllösi, S. Damjanovich, T.M. Jovin, Activation-dependent clustering of the erbB2 receptor tyrosine kinase detected by scanning near-field optical microscopy, J. Cell. Sci. 112 (1999) 1733-1741.

[36] R. Brock, T.M. Jovin, Heterogeneity of signal transduction at the subcellular level: microsphere-based focal EGF receptor activation and stimulation of Shc translocation, J. Cell Sci. 114 (2001) 2437 2447.

[37] P.J. Verveer, F.S. Wouters, A.R. Reynolds, P.I. Bastiaens, Quantitative imaging of lateral ErbB1 receptor signal propagation in the plasma membrane, Science 290 (2000) 1567-1570.

[38] F.G. Haj, P.J. Verveer, A. Squire, B.G. Neel, P.I. Bastiaens, Imaging sites of receptor dephosphorylation by PTP1B on the surface of the endoplasmic reticulum, Science 295 (2002) 1708-1711.

[39] C.Y. Huang, J.E. Ferrell Jr., Ultrasensitivity in the mitogen-activated protein kinase cascade, Proc. Natl. Acad. Sci. USA 93 (1996) 10078 10083.

[40] D. Busse, R.S. Doughty, T.T. Ramsey, W.E. Russell, J.O. Price, W.M. Flanagan, L.K. Shawver, C.L. Arteaga, Reversible G1 arrest induced by inhibition of the epidermal growth factor receptor tyrosine kinase requires upregulation of p27KIP1 independent of MAPK activity, J. Biol. Chem. 275 (2000) 6987-6995.

[41] B. Liu, M. Fang, M. Schmidt, Y. Lu, J. Mende Isohn, Z. Fan, Induction of apoptosis and activation of the caspase cascade by anti-EGF receptor monoclonal antibodies in DiFi human colon cancer cells do not involve the c-jun $\mathrm{N}$-terminal kinase activity, Br. J. Cancer 82 (2000) 1991-1999.

[42] H. Modjtahedi, K. Affleck, C. Stubberfield, C. Dean, EGFR blockade by tyrosine kinase inhibitor or monoclonal antibody inhibits growth, directs terminal differentiation and induces apoptosis in the human squamous cell carcinoma HN5, Int. J. Oncol. 13 (1998) 335-342.

[43] E.S. Kim, F.R. Khuri, R.S. Herbst, Epidermal growth factor receptor biology (IMC-C225), Curr. Opin. Oncol. 13 (2001) 506-513.

[44] J. Albanell, J. Codony-Servat, F. Rojo, J.M. Del Campo, S. Sauleda, J. Anido, G. Raspall, J. Giralt, J. Rosello, R.I. Nicholson, J. Mendelsohn, J. Baselga, Activated extracellular signal-regulated kinases: association with epidermal growth factor receptor/transforming growth factor alpha expression in head and neck squamous carcinoma 
and inhibition by anti-epidermal growth factor receptor treatments, Cancer Res. 61 (2001) 6500-6510.

[45] E.D. Adamson, EGF receptor activities in mammalian development, Mol. Reprod. Dev. 27 (1990) 16-22.

[46] J. Baselga, D. Pfister, M.R. Cooper, R. Cohen, B. Burtness, M. Bos, G. D'Andrea, A. Seidman, L. Norton, K. Gunnett, J. Falcey, V. Anderson, H. Waksal, J. Mendelsohn, Phase I studies of anti-epidermal growth factor receptor chimeric antibody C225 alone and in combination with cisplatin, J. Clin. Oncol. 18 (2000) 904-914.

[47] R.S. Herbst, A.M. Maddox, M.L. Rothenberg, E.J. Small, E.H. Rubin, J. Baselga, F. Rojo, W.K. Hong, H. Swaisland, S.D. Averbuch, J. Ochs, P.M. LoRusso, Selective oral epidermal growth factor receptor tyrosine kinase inhibitor ZD1839 is generally well-tolerated and has activity in non-small-cell lung cancer and other solid tumors: results of a phase I trial, J. Clin. Oncol. 20 (2002) 3815-3825.

[48] F.M. Sirotnak, M.F. Zakowski, V.A. Miller, H.I. Scher, M.G. Kris, Efficacy of cytotoxic agents against human tumor xenografts is markedly enhanced by coadministration of ZD1839 (Iressa), an inhibitor of EGFR tyrosine kinase, Clin. Cancer Res. 6 (2000) 4885-4892.

[49] P. Ahlquist, RNA-dependent RNA polymerases, viruses, and RNA silencing, Science 296 (2002) 1270-1273.

[50] T. Sijen, J. Fleenor, F. Simmer, K.L. Thijssen, S. Parrish, L. Timmons, R.H. Plasterk, A. Fire, On the role of RNA amplification in dsRNA-triggered gene silencing, Cell 107 (2001) 465-476. 